\title{
Hannah Arendt y la participación ciudadana en México
}

\author{
Lukasz Czarnecki \\ Instituto de Investigaciones Económicas de la UNAM
}

http://dx.doi.org/10.5209/rev_NOMA.2014.v42.n2.48774

\begin{abstract}
Resumen.- Hannah Arendt es una pensadora que en los últimos años ha cobrado relevancia en el ámbito de la filosofía política gracias a sus sugerentes reflexiones sobre el totalitarismo, la revolución, la naturaleza de la libertad, la condición humana, por mencionar algunos campos. Se trata, sin duda, de una de las filósofas políticas más sugerentes del pasado siglo XX. En el artículo se propone a leer a Arendt a la luz de Kant y Heidegger. Además, desde esta perspectiva, se introduce la pregunta, ¿cuál es la relación entre el pensamiento de Arendt y la cuestión mexicana?
\end{abstract}

Palabras claves.- Arendt, Kant, Heidegger, México, América Latina, democratización

\begin{abstract}
Hannah Arendt is a thinker who has gained importance in the field of political philosophy thanks to her evocative reflections on the totalitarianism, the revolution, the nature of freedom, the human condition, to name a few fields in recent years. This is undoubtedly one of the most inspiring political philosophers of the twentieth century. The article proposes to read Arendt in the light of Kant and Heidegger. Moreover, from this perspective, it introduces the question, how is the relation between Arendt's thoughts and Mexico?
\end{abstract}

Keywords.- Arendt, Kant, Heidegger, Mexico, Latina America, and democratization

\section{Introducción}

Arendt es una pensadora que en los últimos años ha cobrado relevancia en el ámbito de la filosofía política gracias a sus sugerentes reflexiones sobre el totalitarismo, la revolución, la naturaleza de la libertad, la condición humana, por mencionar algunos campos. Se trata, sin duda, de una de las filósofas políticas más sugerentes del pasado siglo XX. En el artículo se propone a leer a Arendt a la luz de Kant y Heidegger. Después, se analizará el pensamiento de Arendt en torno a su utilidad en México. En este sentido, el artículo será dividido en cinco partes: 1) Introducción, 2) Arendt y Kant, 3) Arendt y Heidergger, 4) Arendt y la cuestión mexicana, y 5) Conclusión.

\section{2) Arendt y Kant}

El problema central del pensamiento de Immanuel Kant (1724-1804) fue la libertad (Freiheit). En la nota al pie, al principio de la introducción de la Critica de la razón practica, Kant hace la división entre "ratio essendi" y "ratio cognoscendi", donde la libertad es "ratio essendi" de la ley moral, y la ley moral es "ratio cognoscendi" de libertad (Kant, 1950:119). Esa unidad, cuyo 
fundamento está en la libertad, es la fuente de derecho. Entre Dios, la inmortalidad del alma y la libertad trascendente (transcendental freedom), la última tiene la función especial. La libertad es un fenómeno porque solamente se puede "estar en ella" a través de la praxis, a diferencia de noúmeno. La libertad es absoluta, no tiene ninguna condición; es espontánea y eterna (timelessness) en el sentido de "estar fuera del tiempo". Finalmente, la libertad es transcendente. A través de la observación de las personas que actúan moralmente podemos conocer la libertad trascendente. Esta infinita libertad, según Hannah Arendt (1998:18-19), está en cada uno de nosotros, en cada ser humano. La libertad pertenece al ser humano sine qua non de la existencia. Gracias a la libertad, las cosas producidas por los hombres: trabajos (works), hechos (deeds) y palabras (words), según Arendt, pueden "encontrar su lugar en el cosmos donde todo es inmortal, excepto ellos mismos". Arendt reconoce la influencia de Kant y advierte que los hombres "por su capacidad para la escritura inmortal, por su capacidad para no dejar huellas atrás, a pesar de su mortalidad individual, alcanzan una inmortalidad de si mismos y demuestran ser la creatura divina" (Arendt, 1998:19). La libertad, a su vez, se relaciona con la razón (Vernunft). El análisis de la razón para Kant lleva a la verdadera religión (Vernunftreligion), aquella en la que Dios es la Razón. La libertad también lleva a la paz perpetua. Kant (1795) postula la creación de una Constitución republicana, en la cual se encuentran: 1) principios de la libertad de los miembros de la sociedad, 2) principios de la dependencia de la legislación común como sujetos, 3 ) la ley confiere igualdad de ciudadanos.

Según Kant los actos no pueden ser universalizados, pero las máximas sí; el acto es fenomenal, una situación empírica. La libertad transcendente es necesaria, ya que el ser humano es la causa de la acción. La felicidad y la virtud son el "Bien Supremo". La analogía para la felicidad es la paz en la mente, eso tienen las personas con virtud.

Lo que destaca en la obra de Kant ([1787], 1995:A798) es la visión transcendental: el concepto de Das Fürwahrhalten (tomando algo como si hubiera sido la verdad, pero nunca como la verdad total). El último deseo de la razón en su uso transcendental es una contemplación de tres objetos: la libertad de la voluntad (Freiheit des Willens), la inmortalidad del alma, y la existencia de Dios (Gott). La libertad tiene un sentido (Verstande) práctico. La libertad nos conecta con la voluntad divina, donde la ley moral nos enseña qué es lo mejor para el mundo (das Weltbeste) en nosotros mismos y en los otros.

Para llegar a la convicción (Uberzeugung) de que algo es verdad (Das Fürwahrhalten) se debe pasar por tres etapas: tener una opinión (Meinen), creer (Glauben), y saber (Wissen). Tener una opinión significa tomar algo como la verdad (Das Fürwahrhalten) con conciencia de que es subjetivamente y objetivamente insuficiente. Cuando es subjetivamente suficiente y objetivamente insuficiente, entonces es Glauben. Cuando Das Fürwahrhalten es al mismo tiempo subjetivamente y objetivamente suficiente, se llama Wissen (Idem, A822/B850). Tomar algo como la verdad tiene dos componentes: objetivos y subjetivos. Si es suficientemente objetivo para todos, es una 
convicción (Uberzeugung). Si se basa solamente en la construcción subjetiva, es una persuasión (Uberredung). Das Fürwahrhalten se relaciona con lo que Hannah Arendt (1977:217) escribe sobre el pensar en el análisis de Critica del juicio (Kritik der Urteilskraft) de Kant: "el poder de juicio yace en el acuerdo potencial con los otros, es decir, depende de la presencia de los otros" lo que Kant Ilama "la mentalidad ampliada" ("enlarged mentality", "eine erweiterte Denkungsart"). Según Ágnes Heller, quien desarrolla el pensamiento arendtiano, la ética está clave: "Necesitamos la ética que nos proporciona una brújula que indique el centro moral. Incluso si todas las normas concretas fallaran, uno debe saber dónde está el centro moral para aproximarse a éste" (Terezakis, 2009:245).

Ahora, Arendt se refiere a Kant en el libro Eichmann in Jerusalem (1977). Para empezar, los artículos de Hannah Arendt publicados en The New Yorker sobre el juicio de Adolf Eichmann durante febrero y marzo de 1963 provocaron muchas controversias tanto que los comentarios influyeron en toda su obra con posterioridad (Rabinbach, 2004:97). La autora presenta la tesis sobre la banalidad del mal, personificada por Adolf Eichmann, el responsable de la ejecución de la política nazi hacia los Judíos. Él asumió el papel de liderazgo en la coordinación de la deportación de los Judíos de todos los rincones de Europa a la Polonia ocupada y la construcción de las cámaras de gas en lugares como Belżec, Chełmno, Sobibor, Treblinka y Auschwitz-Birkenau. Eichmann ni siquiera fue psicópata, ideólogo, o anti-Semita, sino que, según Arendt, su problema consistía en la falta de capacidad de hacer un juicio. Esa falta de satisfacción sobre la banalidad del mal produjo un descontento enorme; primero entre los lectores del The New Yorker (donde Arendt publicaba su relato del juicio) y después de la publicación del libro. Además, Arendt criticaba los Judenrate, los consejos judíos, por las decisiones y acciones en la Europa ocupada por los Nazis. En fin, ¿cómo es posible criticar a los judíos o polacos por la participación negativa durante la guerra? En este sentido, Hannah Arendt fue criticada por el anti-semitismo. Adolf Eichmann confirma ante la corte que sabe lo que es "el imperativo categórico" de Kritik der Praktichen Vernunft, KpV, ([1788] 1967) y de memoria repite las frases. Eichmann pudo contestar durante su proceso que siempre siguió bajo el imperativo categórico: "los principios de mi voluntad tienen que ser siempre aquellos que pueden convertirse en los principios de las leyes generales" (Arendt, 2006:136). Según Arendt, el imperativo categórico kantiano es que cada hombre es legislador en el momento que empieza actuar (act); utilizando su "razón práctica" el hombre encuentra los principios que tienen que o pueden ser los del derecho. 


\section{3) Arendt y Heidegger}

El hombre arendtiano, condenado a la soledad, puede existir a través de la comunicación constante con el otro, a través de las acciones. Esta idea está en deuda con Heidegger. Según Seyla Benhabib (1996:20):

"Las centrales categorías filosóficas de Hannah Arendt, como la acción, la pluralidad y la natalidad, a través de las cuales se define la 'condición humana' están en deuda con Heidegger y, subvertían la ontología heideggeriana. Para Heidegger: ser-para-la-muerte del yo, para Arendt: la natalidad, que todos los hijos también pueden ser iniciadores de la libertad [...]. Considerando que, para Heidegger, 'están con' sigue siendo problemática y, a menudo inauténtica forma de la existencia, para Arendt los seres humanos [...] están en constante comunicación a través del habla, es decir una acción [...]; Para Heidegger, la interacción moral y política no recibe ningún tratamiento ontológico especial. Por el contrario, Arendt es el filósofo de la pluralidad humana, la acción y la natalidad".

Sin embargo, existen diferencias en el pensamiento de ambos filósofos. Para Arendt, el concepto clave es la de "ser de la vida"; por el contrario, para Heidegger en Sein und Zeit es Dasein, ultra-ser incomprensible, el ser humano condenado a la muerte, el "ser de la muerte" (Heidegger, 1977:240). Para Heidegger, la vida es el estado de abandono en el cual el ser humano fue metido en un ya pre-determinado (siempre ya, immer schon, always already), mundo (estar-en-el-mundo, In-der-Welt-sein, Being-in-the-world) (Idem, 53). Lukács (1948), influido por Heidegger, subraya que "la vida misma es el estado de abandono (Geworfenheit) en la "Nada" y en cada momento de esta vida se manifiesta la interacción pseudo-dialéctica de este origen y esta perspectiva final".

La comunicación humana, en el sentido arendtiano crea performance, según el análisis de Elzbieta Matynia (2009), la autora del libro Performative democracy. El poder de la gente hizo posible un cambio: la caída del régimen totalitario en Polonia en 1989, a través de la comunicación en la Mesa Redonda entre los demócratas y los representantes del antiguo régimen; así, mediante el dialogo fue posible la revolución pacífica. También la comunicación se dio a través del arte, el teatro, la escritura, la filosofía, la poesía, etc. Todos estos medios crearon redes de contacto entre la oposición democrática. Hauke Brunkhorst en su libro sobre Hannah Arendt, escribe que la "acción (action) es también la obra del teatro, los discursos, argumentaciones, etc.[...]" (Brunkhorst, 1999:123).

Por su parte, Seyla Benhabib (2004:173) propone un método de la lectura de Arendt que puede caracterizarse como "pensar con Arendt, en contra de Arendt". En otras palabras, Benhabib postula salir de Arendt y ver su pensamiento desde una perspectiva crítica. La tesis de doctorado de Arendt, titulada Der Liebesbegriff bei Augustin: Versuch einer philosophischen Interpretation (2003a, 1996) se divide en tres partes: Amor qua appetitus, Creator - creatura, y Vita socialis, respectivamente. En la última parte, Vita socialis, escribe: "esta nueva Vita socialis, que se basa en Cristo, se define 
como un amor mutuo (diligere invicem), que sustituye la dependencia mutua" (Arendt, 2003a:119-120; Arendt, 1996:108). La vita socialis se vincula directamente con la tradición judeo-cristiana. Además, la cuestión del ser, se refiere a la ultima frontera del pasado a la función obligatoria de la igualdad a través de la cual el amor mutuo es comprensible. Según Arendt:

"La pregunta sobre el ser humano entre los hombres se refiere al bienestar de la raza humana como tal. [...] Sin embargo, mientras el individuo siente que 'todo el camino' estaba 'fuera de este mundo', como miembro de la sociedad humana, siente que incluso todo el camino ha sido mundial. [...] El mundo ya no es un lugar totalmente extraño en el que el individuo ha sido creado. Más bien, por el parentesco de la generación con el mundo siempre ha sido conocido y le pertenece a él. En esta concepción del ser del hombre, podemos entender la función obligatoria de la igualdad" (Arendt, 2003a:115; Arendt, 1996:104).

Dios está en el origen de cada individuo: "Esta cuestión de estar aquí ya es idéntica a la cuestión de la fuente de este ser, que es el origen y la respuesta a esta pregunta es: Dios como el origen respectivo de cada individuo" (Arendt, 2003a:123-124). Esta cuestión de la presencia de Dios es idéntica a la cuestión de la fuente de este ser, pero Arendt sale de la frontera determinada por Dios y al final de su tesis habla sobre un doble origen de los seres humanos: "Damit aber versteht sich das menschliche sein als einem doppelten Ursprung entstammend ("Con esto, el ser humano se deriva de dos fuentes"), (Arendt, 2003a:124; Arendt, 1996:112). ¿De qué fuente (Ursprung) habla Arendt? El hecho (Tatsache) es que el ser humano es condenado a la soledad (isolierter): "El hombre es el otro, si se entiende a sí mismo como un individuo aislado o como condicionado y constituido esencialmente por el hecho de pertenecer a la raza humana" (Idem). El Ursprung del hombre se constituye, según Arendt, a través de un doble proceso contradictorio; Sobre este proceso contradictorio escribe Jorge Luis Borges (1944:180): "Dios está en una de las letras de una de las páginas de uno de los cuatrocientos mil tomos del Clementinum. Mis padres y los padres de mis padres han buscado esta letra; yo me he quedado ciego buscándola".

La contradicción del pensamiento de Arendt no omite su reflección sobre el derecho; para ella, el derecho funciona no como un producto (poiesis), sino como una acción (praxis). En el concepto de derecho, que Arendt desarrolla en Consitutio Libertatis, se distingue entre liberación y libertad: "no hay nada más inútil que la rebelión y la liberación, cuando no van seguidas de la constitución de la libertad recién conquistada" (Arendt, 1973:152); pero, "evidentemente, la palabra 'constitución' es equívoca, porque significa tanto el acto constituyente como la ley o normas de gobierno que son constituidas, [...]" (Idem, 155). La constitución implica todo el proceso desde la convocación de la asamblea constitucional hasta la aceptación de la constitución por el pueblo y su entrada en vigor. 
Arendt se refiere al pensamiento de Heidegger en su concepto de la "revolución". No es la revolución francesa o bolchevique la que le interesa, ya que no trajeron éstas lo esperado, sino que es la revolución donde se encuentra la idea de ser. El ser, escribe Heidegger (2004:39),

"no es ni dios ni un fundamento del mundo. El «ser» está esencialmente más lejos que todo ente y, al mismo tiempo está más próximo al hombre que todo ente, ya sea este una roca, un animal, una obra de arte, una maquina, un ángel o dios. El "ser» es lo más próximo. Pero la proximidad es lo que más lejos le queda al hombre".

Sin lugar de dudad el concepto de ser (Dasein) de Heidegger y la revolución de Arendt se vinculan estrechamente. Arendt (1973: 27) escribe que:

"las revoluciones modernas apenas tienen nada en común con la mutatio rerum de la historia romana, [...], la lucha civil que perturbaba la vida de las polis griegas. No pueden ser identificadas con la metablelike de Platón, es decir la transformación cuasi natural de una forma de gobierno en otra, ni con stasis de Polibio, o sea el ciclo ordenado y recurrente dentro del cual transcurren los asuntos humanos, debido a la inclinación del hombre para ir de un extremo a otro".

\section{4) Arendt y la cuestión mexicana}

Para empezar, la democracia estuvo presente en los territorios del Anáhuac, de los Aztecas en Mesoamérica, y Tawantinsuyu, al igual que en tierras Incas en los Andes antes de la conquista en el siglo XV. ¿Cómo fue la organización política del mundo precolombino? En el periodo 1150-1350 d.C. después del abandono de Teotihuacán y Tula, muchas Ciudades-Estados (altepetl) fueron estableciéndose en el Valle de México. Destacan tres ciudades y las civilizaciones que se desarrollan progresivamente hasta la llegada de los conquistadores españoles: 1) Xochicalco (600-900 d.C.), 2) Malinalco (9001200 d.C.) y 3) Tepoztlan (900-1500 d.C.). Cada ciudad tuvo un centro urbano, con sus territorios aledaños; habían fronteras entre las ciudades; cada altepetl fue gobernado por un tlatoani. Habían uniones (tlatoques) entre altepetlos. Entre 1371 y 1428 comenzó la dominación de Azcapotzalco; finalmente surgió la alianza entre Tlacopan, Texcoco y Tenochtitlán que dominó en la escena política. Durante el Imperio Azteca para 1519 había 489 ciudades en 38 provincias.

¿Cómo fue la organización social en el periodo de los Ciudades-Estados? La historia de los Ciudades-Estados es presentada como la historia de su nobleza; la sociedad fue estratificada. Habían intercambios no solamente entre Ciudades, sino entre entidades geográficamente muy lejanas. Los trabajos arqueológicos en Perú muestran que existía intercambio entre las civilizaciones incaica y azteca. Se encontraron productos de la civilización azteca en Perú y 
al revés. Existieron los intercambios sociales, culturales, mercantiles. Sin embargo, determinar cómo fue el mundo real de Anáhuac y Tawantinsuyu todavía requiere de mucha investigación. ¿Cómo se organizaba la gente en cuanto a la vida económica, social, cultural en éstas ciudades? Las preguntas del pensamiento des-colonial, como lo advierte Walter Mignolo (2003:15), invitan a ver el pasado no como una pureza, sino como el pensamiento fronterizo crítico. En fin, hay que tomar en cuenta el complejo de las preexistentes relaciones políticas, sociales, culturales, que se habían desarrollado antes del periodo del Imperio Español (Hodge, 1984:148).

Había que no temer hacer la pregunta, ¿si hubo democracia en el periodo precolombino? La democracia es un conjunto de instituciones políticas, que están asociadas con un momento histórico particular, actores específicos, y ciertos subconjuntos de los beneficiarios domésticos. La democracia se constituye en un momento del espíritu de la gente, en los tiempo y espacios particulares. En este sentido, la democracia también fue presente en los Ciudades-Estados del Valle de México.

Arendt es la pensadora que invita a hacer la interpretación más realista de la democratización. Esta nueva propuesta debería acabar con las interpretaciones llevabas a cabo dentro de la idea de la democracia que se considera ser del origen griego, latino y cristiano; además resaltando los valores del Occidente. No existe el perfecto a priori sobre la "democracia". En este sentido, también en los territorios de Anáhuac y Tawantinsuyu antes de la llegada de los españoles, existía ésta (Brígida von Mentz, 2008).

Después, en el siglo XVII, fue Sor Juana Inés de la Cruz, antes que Kant, Hegel y la misma Hannah Arendt en el siglo XX, la que ejerció la voz y la palabra de la participación ciudadana en tiempos anteriores, en tiempos en los que no se pudo hablar precisamente de ciudadanía. Cuando llega el nuevo Virrey de la Laguna a la Nueva España, Sor Juana expresó en las palabras de bienvenida, en el argumento del segundo lienzo de Neptuno Alegórico: "Nosotros esperamos mejor Neptuno, que contraponiendo la hazaña forme un Río, por donde fluya una Laguna en su tan necesario, como ingenioso desagüe" (Inés de la Cruz, 1995:295). La ciudadanía significa derechos contra la injusticia y contra la inundación en la gran ciudad de México.

Después, hubo un cambio radical entre el siglo XVII que fue habitado por las palabras de Sor Juana y lo que transcurrió en los tres siglos posteriores. Para referirse al siglo XX y a la historia de los partidos desde 1929, la política fue dominada por el único partido, el PRI (Partido Revolucionario Institucional). Con la democratización, a partir de los años ochentas, la alternancia y el pluralismo partidario tomaron lugar. También, desde este periodo se impuso la política neoliberal; se comenzó con la implementación de las políticas neoliberales desde el sexenio del presidente Miguel de la Madrid (1982-1988). Sin embargo, aunque el proceso de la democratización y la ciudadanización en México se hace cada vez más presente, los "dedazos" y los "destapes", por lo menos 
desde 1969 las seis sucesiones desde Echeverría hasta Zedillo "conviene clasificar en dos categorías; primera: los "dedazos" por eliminación, que beneficiaron a Echeverría en 1969-1970, a Miguel de la Madrid en 1981-1982 y, en la supuesta madre de todos los descartes, a Ernesto Zedillo en 1994. Segunda categoría: los "destapes" por elección o decisión, que favorecieron a Portillo en 1975-1976, a Gortari en 1987-1988 y, de modo efímero, a Colosio en 1993" (Castañeda, 2000:323). Actualmente los "dedazos" los hacen otros grupos de poder, como son los medios de comunicación: Televisa y TV Azteca, entre otros (Cantú, 2011; Villamil, 2011). También, la participación ciudadana es una participación limitada donde solamente se recibe un apoyo económico y se basa en la individualización gracias a la influencia del Banco Mundial (2004). La participación ciudadana se ve reducida a recibir los beneficios monetarios provenientes del gasto público, señalando que "el presupuesto federal en México es un medio importante de acción redistributiva" (Idem, 189).

En fin, existen controversias respecto de hasta dónde hubo un verdadero cambio democrático con la discontinuidad o continuidad de las formas anteriores de gobernar. Las desigualdades persistentes que nutren la pobreza en la sociedad mexicana se relacionan con la presencia de "aves nocturnas", según las palabras de Sor Juana Inés de la Cruz en el Primero Sueño ${ }^{1}$. Como las "aves nocturnas" remiten a los delitos morales y a la corrupción, así las "aves nocturnas" de la realidad contemporánea en México no quieren reconocer al Estado mexicano con sus instituciones democráticas, los derechos de los ciudadanos, sino que tratan al Estado como un medio para incrementar tanto su riqueza económica como su poder político; a saber, son los multimillonarios que dominan la economía mexicana: Carlos Slim Helú, propietario de Telmex, Telcel, América Movil, del centro histórico de la Ciudad de México, entre otros, Emilio Azcárraga Jean, propietario de Grupo Televisa y Ricardo Salinas Pliego, propietario de TV Azteca, Electra y telefonía celular lusacell, entre otros los grandes empresarios que controlan bienes y servicios básicos, como: petróleo, cemento, cerveza, harina de maíz, distribución de medicamentos, etcétera. Según Eduardo P. Motta, el presidente de la Comisión Federal de Competencia, quien castigó a Slim Helú con la multa de mil millones de dólares, los multimillonarios "piensan que es un país de favores, las amistades y los privilegios"; además, "las grandes empresas creen que cuando la ley se aplica a ellos es a causa de animosidad personal y que la ley sólo se

\footnotetext{
1 "Piramidal, funesta, de la tierra / nacida sombra, [...]" (Inés de la Cruz, 1951:335). Según Octavio Paz (1982:486), "es la imagen del mundo sublunar, donde imperan el accidente, la corrupción y el pecado". Aparecen las "aves nocturnas, tan obscuras, tan graves, que aun el silencio no se interrumpía [...]" (Inés de la Cruz, versos 22-24). Las aves en el Primero Sueño de Sor Juana se refieren a mitología: Nictimene - lechuza, hijas de Minias - murciélagos, y Ascáfalo - búho. La transformación en aves, es decir, el castigo que ellos reciben, es por una causa, subraya Buxó, "de su delación sacrílega"; pero no solo de lo sacrílego, "sino que de lo desacordado y confuso" (Pascual Buxó, 2006:116). La avergonzada Nictimene - por el pecado incestuoso, las "atrevidas" hijas de Minias - por no participar en las fiestas del Baco, y Ascáfalo - por ser el delator de Proserpina (castigo por indiscreción). Así, subraya Pascual Buxó (2006:348-349), "se alude a los más graves delitos morales: el incesto, el sacrilegio, la delación falsaria". Las tres hijas de Minias fueron convertidas en murciélagos, ya que se niegan a participar en los festejos de Baco; es un castigo por inobediencia y significan "a los hombres " de mala fama que se esconden y temen el juicio ajeno " "(Idem, 388): "a la deidad de Baco inobedientes, [...]/aves sin pluma aladas/ aquellas tres oficiöosas, digo,/atrevidas Hermanas".
} 
aplica a sus enemigos"; en este contexto, "el resultado de los altos precios, sostiene Pérez Motta, endurece la brecha entre ricos y pobres en México, ya que obligan a las familias pobres a gastar más de sus ingresos en productos básicos" (Malkin, 2011:B1). Sin embargo, a pesar de las palabras atinadas de Pérez Motta, se condonó la multa a Slim (El Universal, 2012). Son poderosas las "aves nocturnas". 


\section{5) Conclusiones}

El 18 de abril de 1975 en Copenhague, Hannah Arendt (2003b:12) habló sobre el origen de la palabra "persona": es un actor que actuando da sonido. De la palabra "sonido" se deriva la palabra "persona": per-sonare, es decir, "dar el sonido a través de". El "sonido" se relaciona con la idea de pensar que, es la actuación del ser humano en el lugar de cada uno. Pensar es expresar concepciones o reconstrucciones del mundo para tomar la decisión, un juicio (judgment). La realidad de uno se funda con diferentes representaciones que construyen a la vez nuestra propia realidad a través del proceso de cognición: "yo pienso", "I think", "Ich denke", "Ik denk", "Je pense", "Myslím že", “Я думаю", "Credo che", "Ja myślę".

Es el acto de pensar "en conjunto". Esta emoción de la mente que hace conciencia del acto de pensar, para finalmente tomar el acto de juicio con una dimensión mística. Este proceso está siempre en marcha, entonces nunca hay que esperar una decisión final, sino que el acto espontáneo del pensar. ¿Puede ser útil la tesis de Arendt sobre Adolf Eichmann, es decir la importancia del "pensar" para la transformación democrática en México? Adolf Eichmann confirmó que supo sobre la ley moral, lo que hace simplemente es decir de memoria una frase, un cliché, un epokhe. En lugar de pensar, Eichmann repite las palabras.

En el caso de México, se implementan las políticas neoliberales en la forma más cruel, como el resultado la mayoría de la gente sufre la pobreza y las desigualdades; siguen presentes "las aves nocturnas". Según Arendt: "Cultura y política pertenecen conjuntamente porque no es la verdad o el conocimiento el que está en juego, sino el juicio (judgment) y la decisión, el intercambio juicioso de opinión acerca de la esfera de la vida pública y el mundo común, y la decisión de qué clase de acción se toma, así como a la forma de mirar adelante" (Arendt, 1977:219-220). Todavía en México queda mucho por implementar los juicios y las decisiones realmente democráticas.

\footnotetext{
${ }^{2}$ En la tercera parte „Gianni Schicchi” de la opera II trittico de Puccini conocemos el mundo de la Florencia del siglo XX (Puccini establece el año exacto de 1959). Veamos la familia italiana en el momento de conocer el testamento de Buoso Donato. Los miembros son muy codiciosos, sin la ética o la ley moral y el testamento refleja esta triste verdad: Buoso Donato hace donación para la Iglesia. Desde este momento los familiares quieren cambiar el testamento, por eso llaman a Gianni Schicchi para que tomara la decisión. Ellos mismos no saben, no pueden tomar la decisión. Gianni lega y presenta el misterioso plan. Después de disfrazarse de Buso Donato llegan el doctor y el abogado. En fin, Gianni disfrazado por Buoso, como si la salud le permitiera, cambia el testamento. La falta de la ley moral significa la falta de capacidades de utilizar la Razón, de pensar. Los familiares repiten un cliché, no saben tomar la decisión.
} 


\section{Bibliografía:}

ARENDT, H. (2006), Between Past and Future, New York, Penguin Book.

- (1977), Eichmann in Jerusalem: a report on the banality of evil, New York, Penguin Books.

- (1998), Human Condition, Chicago, The Chicago University Press.

- (1996), Love and Saint Augustine, Chicago, University of Chicago Press.

- (2003a), Der Liebesbegriff bei Augustin: Versuch einer philosophischen Interpretation, Berlin, Philo.

- (2003b, )Responsibility and judgment, New York, Schocken Books.

- (1973), Sobre la revolución, Madrid, Alianza.

BENHABIB, Seyla, (1996), The reluctant modernism of Hannah Arendt, Thousand Oaks, California, Sage Publications.

- (2004), "Kantian Questions, Arendtian Answers: Statelessness, Cosmopolitanism, and the Right to Have Rights" en Benhabib, Seyla and Fraser, Nancy (eds.), Pragmatism, critique, judgment: essays for Richard J. Bernstein, Cambridge, Mass., MIT Press.

BORGES, Jorge Luis, (1944), “El milagro secreto” en Artificios, Madrid, Alianza. BRUNKHORST, Hauke, (1999), Hannah Arendt, München, C. H. Beck.

CANTÚ, Jesús, (2011), "El dedazo de Televisa” en Proceso, No.1794, el 20 de marzo.

CASTAÑEDA, Jorge, (2000), La Herencia. Arqueología de la sucesión presidencial en México, México: Extra Alfaguara.

EL UNIVERSAL, (2012), "Telcel cambia 'megamulta' por cinco compromisos", el 3 de mayo: http://www.eluniversal.com.mx/notas/845086.html (acceso el 11 de junio de 2012).

INÉS DE LA CRUZ, Sor Juana, (1995), "Neptuno Alegórico", en Inundación castálida, México: Instituto Mexiquense de Cultura.

Kant, Immanuel, (1967), Kritik der Praktichen Vernunft, Hamburg, Felix Meiner Verlag.

Kant, Immanuel, ([1787]1995), Kritik der Reinen Vernunft, Frankfurt, Suhrkamp.

- ([1788]1995), KpV, Frankfurt, Suhrkamp.

- (1950), Critique of practical reason, Chicago, The University of Chicago Press.

TEREZAKIS, Katie eds. (2009), Engaging Agnes Heller: A critical companion, Lanham, MD, Lexington Books.

HEIDEGGER, Martin, (1977), Sein und Zeit, Tubingen, Niemeyer.

LUKÁCS, György, (1948), ¿Existentialisme ou marxisme? Paris, Collection Pensées. 
MATYNIA, Elzbieta, (2009), Performative democracy, London, Paradigm Publishers, Yale cultural sociology series.

HEIDEGGER, Martin, (2004), Carta sobre el Humanismo, Madrid, Alianza.

HODGE, Mary G., (1984), "Aztec City-States", en Memoirs of the museum of Anthropology University of Michigan, No. 18, Vol. 3, Ann Arbor.

MALKIN, Elisabeth, (2011), "Mexico takes aim at a titan in Telecom", en New York Times, el 9 de mayo.

MENTZ, Brígida von, (2008), Cuauhnáhuac 1450-1675 su historia indígena y documentos en "mexicano" : cambio y continuidad de una cultura nahua, México DF: M. A. Porrúa.

MIGNOLO, Walter, (2003), Interculturalidad, descolonizacion del estado y del conocimiento, Duke Univesrity.

PASCUAL BUXÓ, José, (2006), "Sor Juana y Góngora: teoría y práctica de la imitación poética" en Sor Juana Inés de la Cruz. Lectura barroca de la poesía, Ed. Renacimiento.

PAZ, Octavio, (1982), Sor Juana Inés de la Cruz o las trampas de la fe, México: FCE.

RABINBACH, Anson, (2004), "Eichmann in New York: The New York Intellectuals and the Hannah, Arendt Controversy" en October, The MIT Press, Vol. 108.

VILLAMIL, Jenaro, (2011), "Dedazo dinástico: en Proceso, No.1795, el 27 de marzo. 